\title{
Open repair with bad lungs? Don't hold your breath!
}

Although there have been important and significant improvements in operative strategies and postoperative results for open thoracoabdominal aortic aneurysm repair, ${ }^{1,2}$ problems undeniably remain, and thus, some still question the value of this therapy. In contemporary practice, however, despite emerging experimental endovascular therapy for thoracoabdominal aortic aneurysms and its potential for widespread adoption after the successful completion of related clinical trials, open repair remains the criterion standard.

Among the problems open surgical repair presents is that of patients with markedly reduced pulmonary function stemming from chronic obstructive coronary disease, emphysema, and other pulmonary conditions, or secondary to tobacco and age. ${ }^{3,4}$ Girardi and colleagues ${ }^{5}$ address this problem in this issue of The Journal of Thoracic and Cardiovascular Surgery by reviewing their experience of 711 patients undergoing open descending thoracic or thoracoabdominal aortic aneurysm repair. Notably, this is a large series from a very experienced and well-developed aortic program; their overall mortality was excellent at $5.6 \%$ (40/711), and major complications occurred in only 75 patients $(10.5 \%)$. Unadjusted mortality, as expected, was higher for those patients undergoing hypothermic circulatory arrest (14.8\%) during repair as well as for those with extent II aneurysms (13.3\%). On logistic regression analysis, patients with a preoperative forced expiratory volume in 1 second $\left(\mathrm{FEV}_{1}\right)$ of $50 \%$ or less were associated with a 6.99-fold increase in their risk of developing major adverse events, which led to a propensity score analysis of 149 pairs of patients with $\mathrm{FEV}_{1} 50 \%$ and below compared with those above $50 \%$. After propensity score matching, Girardi and colleagues ${ }^{5}$ found that operative mortality was nearly twice for those with an $\mathrm{FEV}_{1}$ of $50 \%$ or less than for those with an $\mathrm{FEV}_{1}$ value greater than $50 \%$ ( $11.4 \%$ vs $6.0 \%$, respectively). In addition, for those with reduced preoperative lung function the incidence of major complications was $33.1 \%$, versus $19.5 \%$ in those with $\mathrm{FEV}_{1}$ greater than $50 \%$. In both matched groups the need for tracheostomy was a common major adverse event,

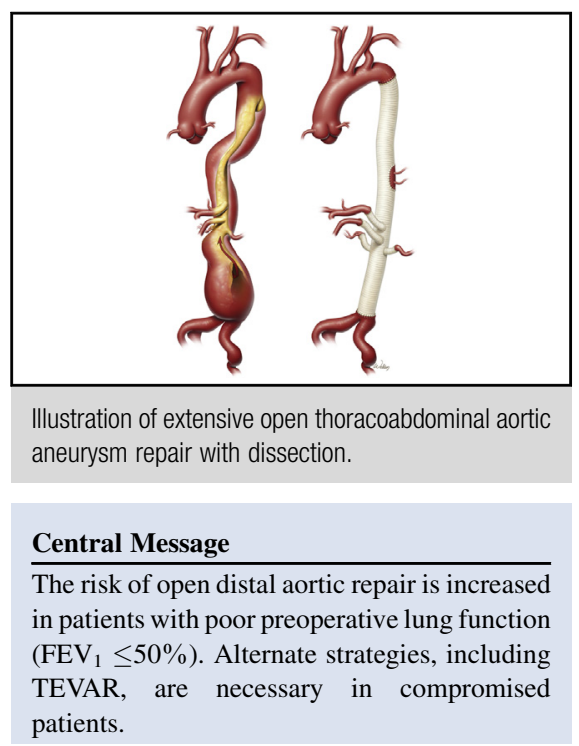

See Article page S22.

with an incidence of $16.1 \%$ among those with poor lung function $\left(\mathrm{FEV}_{1} \leq 50 \%\right)$.

That patients with poor lung function routinely undergo complex open aortic repair is underscored by the fact that in the overall group of 711 patients, more than $40 \%$ had chronic pulmonary disease and more than $20 \%$ of patients had spirometry testing with an $\mathrm{FEV}_{1}$ of $50 \%$ or less. This certainly justifies the evaluation of additional risk related to open surgery in the current era, because many patients have significant lung pathology. Because significant strides have been made in reducing early mortality, spinal cord ischemic problems, and postoperative renal failure, it is indeed logical to address improving pulmonary function. Girardi and colleagues ${ }^{5}$ clearly point out that in patients requiring total cardiopulmonary bypass with hypothermic circulatory arrest, there is an increased risk of postoperative pulmonary failure as a consequence of not only potentiation of the inflammatory effects of ischemia and bypass but also of the deleterious mechanical impact of retracting the left lung in a fully heparinized patient, which is typically necessitated in open descending thoracic and thoracoabdominal aortic repair.

In contemporary repair, most straightforward descending thoracic aortic aneurysms and some cases of thoracoabdominal aortic aneurysms (with and without aortic dissection) are now managed with endovascular aortic repair, 6,7 which intrinsically provides less risk from a pulmonary standpoint by obviating both the need to provide cardiopulmonary bypass and the need to retract the left 
lung. For patients with descending thoracic aneurysm and reduced lung function - even those who are considered at low risk in all other aspects-endovascular therapy should be the primary consideration unless contraindicated by coexisting connective tissue disorders. In time (and with widespread availability of branched and fenestrated endovascular thoracoabdominal aortic devices), we will have a better understanding of patients with thoracoabdominal aortic aneurysms who may benefit from endovascular repair rather than traditional open repair. All programs pursuing open therapy should regularly review their preoperative evaluation, operative technique, and postoperative care to develop strategies to reduce the morbidity of patients with compromised lung function $\left(\mathrm{FEV}_{1} \leq 50 \%\right)$. With a population that is increasing in age and all the comorbidities that go along with such aging, particularly lung function, the results of these patients speak to the need to develop alternate aortic repair paradigms in patients with poor lung function, including establishing safe and durable total endovascular therapy.

\section{References}

1. Coselli JS, LeMaire SA, Preventza O, de la Cruz KI, Cooley DA, Price MD, et al Outcomes of 3309 thoracoabdominal aortic aneurysm repairs. J Thorac Cardiovasc Surg. 2016;151:1323-38.

2. Kouchoukos NT, Kulik A, Castner CF. Outcomes after thoracoabdominal aortic aneurysm repair using hypothermic circulatory arrest. J Thorac Cardiovasc Surg. 2013;145(3 Suppl):S139-41.

3. Aftab M, Songdechakraiwut T, Green SY, Zarda S, Price MD, Nalty CC, et al. Contemporary outcomes of open thoracoabdominal aortic aneurysm repair in octogenarians. J Thorac Cardiovasc Surg. 2015;149(2 Suppl):S134-41.

4. Di Luozzo G, Shirali AS, Varghese R, Lin HM, Weiss AJ, Bischoff MS, et al. Quality of life and survival of septuagenarians and octogenarians after repair of descending and thoracoabdominal aortic aneurysms. J Thorac Cardiovasc Surg. 2013;145:378-84.

5. Girardi LN, Lau C, Munjal M, Elsayed M, Gambardella I, Ohmes L, et al. Impact of preoperative pulmonary function on outcomes after open repair of descending and thoracoabdominal aortic aneurysms. J Thorac Cardiovasc Surg. 2017;153: S22-9.

6. Scali ST, Goodney PP, Walsh DB, Travis LL, Nolan BW, Goodman DC, et al National trends and regional variation of open and endovascular repair of thoracic and thoracoabdominal aneurysms in contemporary practice. J Vasc Surg. 2011;53: 1499-505.

7. Liao JM, Bakaeen FG, Cornwell LD, Simpson K, Lemaire SA, Coselli JS, et al. Nationwide trends and regional/hospital variations in open versus endovascular repair of thoracoabdominal aortic aneurysms. J Thorac Cardiovasc Surg. 2012; 144:612-6. 